\title{
Synthesis of L-Ascorbyl Flurbiprofenate by Lipase-Catalyzed Esterification and Transesterification Reactions
}

\author{
Jia-ying Xin, ${ }^{1,2}$ Li-rui Sun, ${ }^{1}$ Shu-ming Chen, ${ }^{3}$ Yan Wang, ${ }^{1}$ and Chun-gu Xia ${ }^{2}$ \\ ${ }^{1}$ Key Laboratory for Food Science \& Engineering, Harbin University of Commerce, Harbin 150076, China \\ ${ }^{2}$ State Key Laboratory for Oxo Synthesis \& Selective Oxidation, Lanzhou Institute of Chemical Physics, Chinese Academy of Sciences, \\ Lanzhou 730000, China \\ ${ }^{3}$ College of Animal Science and Veterinary Medicine, Shanxi Agricultural University, Taigu 030801, China
}

Correspondence should be addressed to Jia-ying Xin; xinjiayingvip@163.com

Received 17 May 2016; Accepted 31 July 2016; Published 21 March 2017

Academic Editor: Bidur P. Chaulagain

Copyright (C) 2017 Jia-ying Xin et al. This is an open access article distributed under the Creative Commons Attribution License, which permits unrestricted use, distribution, and reproduction in any medium, provided the original work is properly cited.

\begin{abstract}
The synthesis of L-ascorbyl flurbiprofenate was achieved by esterification and transesterification in nonaqueous organic medium with Novozym 435 lipase as biocatalyst. The conversion was greatly influenced by the kinds of organic solvents, speed of agitation, catalyst loading amount, reaction time, and molar ratio of acyl donor to L-ascorbic acid. A series of solvents were investigated, and tert-butanol was found to be the most suitable from the standpoint of the substrate solubility and the conversion for both the esterification and transesterification. When flurbiprofen was used as acyl donor, $61.0 \%$ of L-ascorbic acid was converted against $46.4 \%$ in the presence of flurbiprofen methyl ester. The optimal conversion of $\mathrm{L}$-ascorbic acid was obtained when the initial molar ratio of acyl donor to ascorbic acid was 5:1. kinetics parameters were solved by Lineweaver-Burk equation under nonsubstrate inhibition condition. Since transesterification has lower conversion, from the standpoint of productivity and the amount of steps required, esterification is a better method compared to transesterification.
\end{abstract}

\section{Introduction}

The treatment of Alzheimer's disease is still a major challenge for the medical field. The clinical failure of efficient Alzheimer's disease drug delivery may be largely attributed to the low permeability of drugs due to the blood-brain barrier and a lack of appropriate drug delivery systems [1]. Flurbiprofen is one of the most potent nonsteroidal anti-inflammatory drugs (NSAIDs) and may help to prevent Alzheimer's disease $[2,3]$. However, poor brain delivery of flurbiprofen and its serious gastrointestinal side effects have hampered the application of flurbiprofen as neuroprotective agents [4].

Localized and controlled delivery of drugs at their desired site of action can reduce toxicity and increase treatment efficiency. L-Ascorbic acid is essential for many enzymatic reactions, which is transported directly across the blood-brain barrier via Nap-dependent vitamin C transporter SVCT2 and particularly prevalent in the brain [1]. It has been reported that L-ascorbic acid could be used as a carrier to promote brain drug delivery [5-7]. To overcome the problems of the low blood-brain barrier permeability of flurbiprofen and to increase its delivery to the brain for the treatment of Alzheimer's disease, one attractive approach is to design and synthesize flurbiprofen ester prodrug named L-ascorbyl flurbiprofenate containing ascorbate as a specific carrier system for brain delivery.

So far, there are very few reports on the lipase-catalyzed synthesis of L-ascorbyl flurbiprofenate. Wang and Tang studied the synthesis of L-ascorbyl flurbiprofenate by lipasecatalyzed esterification of L-ascorbic acid with flurbiprofen in tertiary amyl alcohol but no optimum operating parameters were provided [8]. Liu and Tang investigated the kinetics and thermodynamics of the lipase-catalyzed esterification of L-ascorbic acid with flurbiprofen in 2-methy-1,2butanol [9]. Only limited information on the lipase-catalyzed esterification was available. There were no reports on the lipase-catalyzed synthesis of L-ascorbyl flurbiprofenate by transesterification. However, solvent properties, quantity of enzyme, and molar ratio of L-ascorbic acid to flurbiprofen may influence the biocatalytic reaction. So far, the influence 
of these factors for the synthesis of L-ascorbyl flurbiprofenate has not been investigated in detail. To obtain high conversion, it is important to determine the optimal reaction conditions and understand the kinetics parameters.

The present study focused on lipase-catalyzed synthesis of L-ascorbyl flurbiprofenate. The lipase-catalyzed esterification and transesterification approaches have been compared. It was worthwhile to compare the merits and demerits of the two processes and optimize process conditions.

\section{Experimental}

2.1. Materials. Novozym 435 lipase (Lipase B from Candida antarctica immobilized on macroporous acrylic resin; specific activity: 10,000 U/g) was purchased from Novozymes, Denmark. Porcine pancreas lipase Type II (powder, 30-90 U/mg) and Candida rugosa lipase (Type VII, powder, $706 \mathrm{U} / \mathrm{mg}$ ) were purchased from Sigma.

$(R, S)$-flurbiprofen (purity $>99 \%$ ) was purchased from Shanghai Mei Lan Chemical Co. Ltd. (Shanghai, China). The purity of substrates is over $99.7 \%$ for L-ascorbic acid. All solvents were dehydrated before use with activated $3 \AA$ molecular sieves. Thin-layer chromatography (TLC) plates were purchased from Merck (KGaA, Darmstadt, Germany).

2.2. Synthesis of Ester. The methyl ester of $(R, S)$-flurbiprofen was prepared by the classical methodology using thionyl chloride and methanol. Thionyl chloride, $15 \mathrm{~mL}(0.20 \mathrm{~mol})$, was added dropwise to cooled, stirred suspension of $(R, S)$ flurbiprofen $(0.12 \mathrm{~mol})$ in methanol $(250 \mathrm{~mL})$. The reaction mixture was refluxed for $2.5 \mathrm{~h}$, and then the solvent was evaporated and the residue purified by column chromatography using $\mathrm{SiO}_{2}$ as adsorbent and petroleum ether purified as eluant and its purity was > 98\% using the HPLC methods described in a later section.

2.3. Reaction Conditions. Unless otherwise stated, the esterification and transesterification reactions were performed in $50 \mathrm{~mL}$ closed, screw-capped glass vials containing $25 \mathrm{~mL}$ of organic solvent, flurbiprofen or flurbiprofen methyl ester (26-260 mmol/L), L-ascorbic acid (26 mmol/L), and $800 \mathrm{mg}$ of molecular sieve $3 \AA$. The reaction had been started by adding $40 \mathrm{mg}$ of lipase. The headspace in the vials was filled with nitrogen gas and refilled after each sampling. The reaction mixture was stirred with a magnetic stirrer at different temperature. In both cases, samples were withdrawn at specified time intervals for measurement of the conversion. Control experiments without enzymes were carried out in parallel.

2.4. Analytical Methods. In order to monitor the reaction progress, samples of $100 \mu \mathrm{L}$ were withdrawn at intervals and analyzed by thin-layer chromatography (TLC) on silica gel $60 \mathrm{~F}_{254}$ plates with fluorescent indicators. The TLC migration was carried out with a solvent mixture of chloroform/methanol/glacial acetic acid/water $(80: 10: 8: 2$, $\mathrm{V} / \mathrm{V} / \mathrm{V} / \mathrm{V})$. The TLC plates were visualized under UV. Results were estimated from intensity of spots on TLC.
Quantitative analysis was done by HPLC (Thermo U3000), on a XDB C18 reversed phase column $(5 \mu \mathrm{m}, 4.6 \times$ $150 \mathrm{~mm}$ ) with acetonitrile/water/formic acid (80/20/0.2, $\mathrm{V} / \mathrm{V} / \mathrm{V}$ ) as mobile phase at $1 \mathrm{~mL} / \mathrm{min}$ flow rate. Detection was achieved using UV detection at $294 \mathrm{~nm}$. Samples were filtered to remove the enzyme and molecular sieves and $100 \mu \mathrm{L}$ of the solution was diluted with acetonitrile/water/formic acid $(80 / 20 / 0.2, \mathrm{~V} / \mathrm{V} / \mathrm{V})$. L-Ascorbic acid was a limiting substrate throughout this study; therefore, the conversion was calculated as the ratio in moles of the product to initial Lascorbic acid. All experiments were performed in triplicate and standard deviations were calculated.

The enantiomeric excess values of flurbiprofen and flurbiprofen methyl ester (ee) were determined by HPLC (Agilent 1200 ) by using a chiral column (Chiralcel OD-H, $5 \mu \mathrm{m}$, $250 \mathrm{~mm} \times 4.6 \mathrm{~mm}$ ) capable of separating the $R$ - and $S$ isomers of flurbiprofen and flurbiprofen methyl ester, and the mobile phase was hexane/isopropanol/trifluoroacetic acid solution $(98: 2: 0.1, \mathrm{~V} / \mathrm{V} / \mathrm{V})$, at a flow rate of $1.0 \mathrm{~mL} / \mathrm{min}$. UV detection at $294 \mathrm{~nm}$ was used for quantification at the $25^{\circ} \mathrm{C}$. The enantiomeric excess (ee) was obtained from peak areas of the $R$ - and $S$-isomers of flurbiprofen or flurbiprofen methyl ester by the following equation: ee $=\left(A_{S}-A_{R}\right) /\left(A_{S}+A_{R}\right)$, where $A_{S}$ is peak areas of the $S$-isomer and $A_{R}$ is peak areas of the $R$-isomer.

2.5. Kinetic Study. Reactions were carried out no more than $5 \%$ conversion and the initial rate was determined as the slope of the reaction curve tangent to the initial stage of the reaction and expressed as mol of products $\mathrm{h}^{-1} \mathrm{~L}^{-1}$. Because all experiments were performed in triplicate, reaction curves were constructed using average values of the reaction rate for each experimental point. A linear portion of the reaction curve at various substrate concentrations consisted of 5 experimental points, where the number of experimental points included was determined by the condition that correlation coefficients of the initial straight line must be above 0.95 .

\section{Results and Discussion}

3.1. Esterification and Transesterification. It was previously reported that esterification of flurbiprofen with L-ascorbic acid by lipase in tert-amyl alcohol produced L-ascorbyl flurbiprofenate regioselectively, which was only the product identified in the HPLC analysis [9]. In this paper, lipase-catalyzed acylation of L-ascorbic acid was performed in presence of racemic flurbiprofen (esterification) or racemic flurbiprofen methyl ester (transesterification). Both kinds of reaction led to only one product identified as L-ascorbyl flurbiprofenate in the HPLC analysis. Furthermore, the chiral HPLC analysis indicated that the lipases also display stereospecificity in the esterification and transesterification. The $R$-isomer reacted with the Novozym 435 lipase; the $S$-isomer reacted with the Candida rugosa lipase and porcine pancreas lipase cannot catalyze the reaction. It has been reported that $S$-flurbiprofen and $R$-flurbiprofen have the same physiological activity in prevention of the development of Alzheimer's disease but $R$ flurbiprofen has reduced side effects related to inhibition of 
TABLE 1: The effect of solvent on the conversion of esterification and transesterification.

\begin{tabular}{lccc}
\hline Solvent & $\log P$ & \multicolumn{2}{c}{$\begin{array}{r}\text { Conversion of L-ascorbic acid (\%) } \\
\text { Transesterification }\end{array}$} \\
\hline Acetone & -0.23 & Esterification & 30.0 \\
Tert-butanol(2-methyl-2-propanol) & 0.60 & 36.0 & 38.5 \\
Ethyl acetate & 0.68 & 11.1 & 9.8 \\
Tert-amyl alcohol; 2-methyl-butanol & 0.89 & 35.3 & 36.5 \\
Benzene & 2.00 & - & - \\
Chloroform & 2.00 & 3.5 & - \\
Toluene & 2.50 & - & - \\
\hline
\end{tabular}<smiles>CC(C(=O)O)c1ccc(-c2ccccc2)c(F)c1</smiles>

$(S, R)$-Flurbiprofen<smiles>CC(C(=O)O)c1ccc(-c2ccccc2)c(F)c1</smiles>

$(S, R)$-Flurbiprofen methyl ester
L-Ascorbic acid

(R)-L-Ascorbyl flurbiprofenate

(a)<smiles>COC(=O)[C@H](C)c1ccc(-c2ccccc2)c(F)c1</smiles>

L-Ascorbic acid

(R)-L-Ascorbyl flurbiprofenate

(b)

FIGURE 1: Novozym 435 lipase-catalyzed esterification (a) and transesterification (b).

cyclooxygenase (COX) [10-12]. Thus, Novozym 435 lipase, identified as a $R$-stereospecific catalyst, has been employed in further experiments. The two reactions for the preparation of L-ascorbyl flurbiprofenate are shown in Figure 1.

3.2. Effect of Solvent. Different organic solvents had different ability to distort the essential water layer around lipase and could greatly influence the activity of lipase. Moreover, organic solvent relatively influenced the solubility of the substrates, and thus it would affect the synthesis of the Lascorbyl flurbiprofenate. The polarity of L-ascorbic acid is very different from those of flurbiprofen and flurbiprofen methyl ester. Because of this significant difference in polarity, such a solvent with relatively high solubility of flurbiprofen, flurbiprofen methyl ester, and L-ascorbic acid needs to be found.
Therefore, esterification and transesterification strategies for the lipase-catalyzed synthesis of L-ascorbyl flurbiprofenate were compared using different organic solvents. The effect of various organic solvents on conversion of Lascorbic acid was studied under similar conditions using $50 \mathrm{mg}$ Novozym 435 lipase, $800 \mathrm{mg}$ of molecular sieve $3 \AA$, 2.3 mmoles of flurbiprofen or flurbiprofen methyl ester, 0.57 mmoles of ascorbic acid, and $25 \mathrm{~mL}$ organic solvent at $160 \mathrm{rpm}$, at $50^{\circ} \mathrm{C}$ for $72 \mathrm{~h}$. It was clear from Table 1 that the type of organic solvent strongly influenced the synthesis of L-ascorbyl flurbiprofenate. In the case of esterification and transesterification, tert-butanol was the best solvent with tertamyl alcohol as the next best. However, the reaction product was not inspected in benzene and toluene.

$\log P$ is widely used to represent the characteristics of the organic solvent system where $P$ is the partition coefficient of 


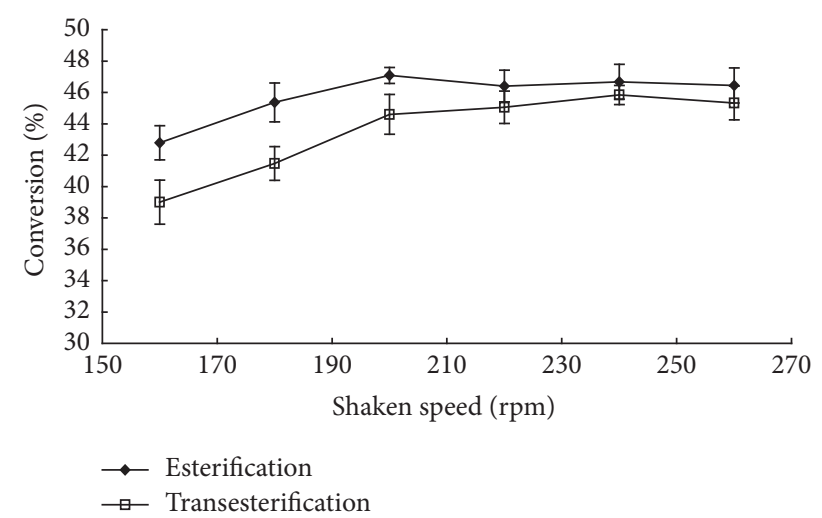

FIGURE 2: The effect of speed of agitation on the conversion of esterification and transesterification.

the solvent between water and octanol [13]. It is generally reported that solvents with $\log P<2$ are high polarity that may strip water from enzyme molecules easily and are less suitable for biocatalytic purpose [14]. In this case, no correlation of the lipase activity with $\log P$ of the solvents could be established. This could be attributed that L-ascorbic acid had very low concentration in solvents with high $\log P$. Since tert-butanol was the optimum solvent for esterification and transesterification, it was used as the solvent for transesterification and esterification in further experiments.

3.3. Effect of Speed of Agitation. In the case of immobilized enzyme, external mass transfer limitations may be important. The reactants have to diffuse from the bulk liquid to the external surface of the catalyst. External mass transfer can be minimized by carrying out the reaction at an optimum speed of agitation. The effect of speed of agitation was studied both for esterification and transesterification over the range of 160-260 rpm by taking $50 \mathrm{mg}$ Novozym 435 lipase, $800 \mathrm{mg}$ of molecular sieve $3 \AA, 2.3$ mmoles of flurbiprofen or flurbiprofen methyl ester, 0.57 mmoles of ascorbic, and $25 \mathrm{~mL}$ tert-butanol at $50^{\circ} \mathrm{C}$ for $72 \mathrm{~h}$. The conversions in both the cases were independent of the speed of agitation at and beyond $180 \mathrm{rpm}$ for esterification and transesterification (Figure 2). This indicated that the influence of external mass transfer limitation was negligible and a speed of agitation of $180 \mathrm{rpm}$ did not limit reaction rate. So all subsequent experiments were carried out at $180 \mathrm{rpm}$.

3.4. Effect of Catalyst Loading Amount. Internal diffusion problems could happen when the substrate could not reach the inner parts of the support. L-Ascorbyl flurbiprofenate synthesis as a function of catalyst loading amount was studied at $50^{\circ} \mathrm{C}$ and $180 \mathrm{rpm}$ for $72 \mathrm{~h}$. The conversion of the reaction increased with increasing immobilized lipase loading ranging from $15 \mathrm{mg}$ to $55 \mathrm{mg}$ in both the cases; a linear relationship between the conversion and enzyme load demonstrated that the internal diffusion limitations could be minimized. Maximal conversion was achieved with $55 \mathrm{mg}$ lipase for esterification and transesterification after conversion became constant and no further increases (Figure 3).

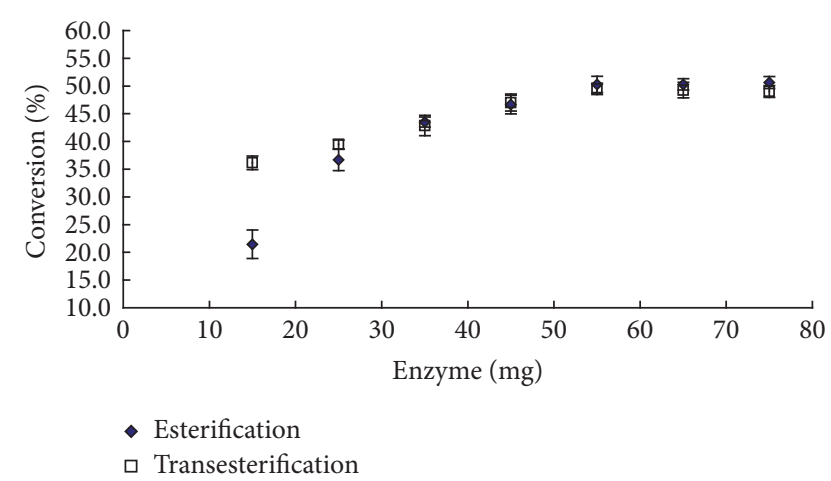

FIgURE 3: The effect of catalyst loading amount on the conversion of esterification and transesterification.

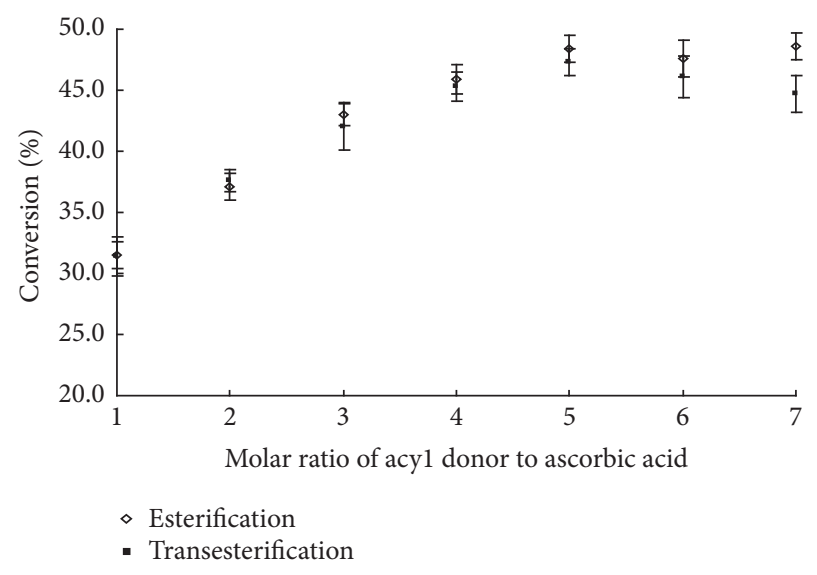

FIGURE 4: The effect of the molar ratio of acyl donor to ascorbic acid on the conversion of esterification and transesterification.

Also, in the case of esterification reaction, the conversion was lower than the transesterification reaction under $15 \mathrm{mg}$ and $25 \mathrm{mg}$ lipase addition and the asymptotes were seen in the conversion for transesterification and esterification when the amount of enzyme added was beyond $35 \mathrm{mg}$. Since there was no significant increase in the conversion with increased catalyst loading from $55 \mathrm{mg}$ to $75 \mathrm{mg}$, further parameters were studied using $55 \mathrm{mg}$ catalyst loading.

3.5. Effect of the Molar Ratio of Acyl Donor to Ascorbic Acid. The molar ratio of one substrate to another is an important parameter affecting the conversion. The solubility of L-ascorbic acid in tert-butanol at $50^{\circ} \mathrm{C}$ was $26 \mathrm{mmol} / \mathrm{L}$, which is saturated in tert-butanol that would be limiting as substrate. Therefore, the effect of the molar ratio of the reactants was studied by keeping the concentration of Lascorbic acid and the catalyst quantity constant and varying the concentration of acyl donor in both esterification and transesterification. Figure 4 showed the effect of the molar ratio on the conversion for the synthesis of L-ascorbyl flurbiprofenate. Molar ratio of acyl donor to ascorbic acid was varied from $1: 1$ to $7: 1$, and the L-ascorbic acid was kept constant. The conversion at a reaction time of $72 \mathrm{~h}$ for 


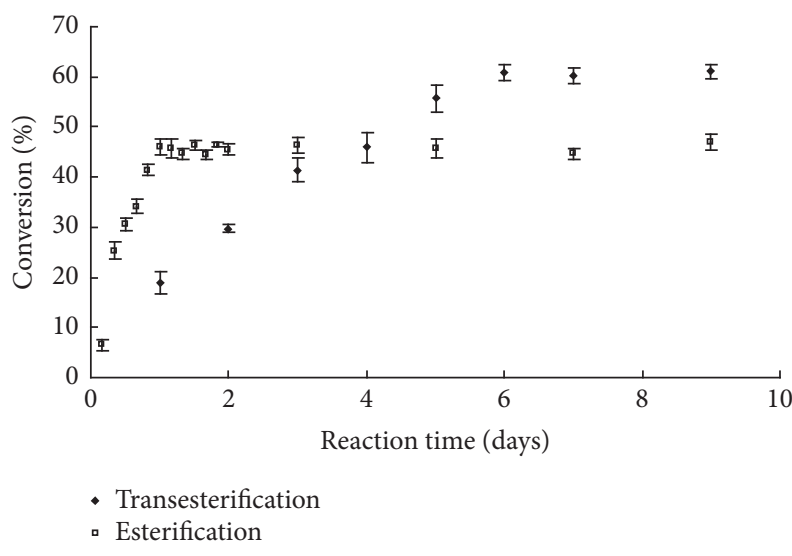

FIGURE 5: Time course of the synthesis of L-ascorbyl flurbiprofenate.

esterification and transesterification was compared. Indeed, within experimental error, at a fixed concentration of Lascorbic acid and loading amount of Novozym 435 lipase, the conversion increased with increasing acyl donor concentrations up to a critical value. For esterification and transesterification, when using higher ratios of flurbiprofen or flurbiprofen methyl ester over L-ascorbic acid, conversion increased and highest conversion (61.0\% for esterification and $46.4 \%$ for transesterification) occurred at 5:1 molar ratio of flurbiprofen or flurbiprofen methyl ester to L-ascorbic acid. At molar ratios greater than $5: 1$, a constant conversion was observed.

3.6. Effect of Reaction Time. Figure 5 showed the changes in the conversion with time for the direct esterification and transesterification in tert-butanol at $50^{\circ} \mathrm{C}$ with molar ratio of acyl donor to ascorbic acid of $5: 1$. Direct esterification and transesterification reaction had a different initial rate and maximal conversion. In the case of transesterification reaction, the rate was faster than that of the esterification reaction under otherwise similar conditions within the reaction time of $24 \mathrm{~h}$. This could be attributed that lipase had higher activity for flurbiprofen methyl ester and lower activity with flurbiprofen. Also the difference consisted in the maximal conversion of L-ascorbic acid, which was $61.0 \%$ occurring after $144 \mathrm{~h}$ of incubation for esterification, against $46.4 \%$ occurring after $72 \mathrm{~h}$ of incubation for transesterification. This difference might be due to methanol production during the transesterification reaction which was not eliminated by the $3 \AA$ molecular sieve and disadvantageous reaction equilibrium for L-ascorbyl flurbiprofenate production. Even if water was also produced as a coproduct during the esterification reaction, the $3 \AA$ molecular sieve favors its elimination by adsorption and then contributes to shift the reaction equilibrium towards the synthesis of L-ascorbyl flurbiprofenate.

3.7. Kinetic Study. The effects of several parameters including organic solvent, speed of agitation, enzyme amount, substrate molar ratio, and reaction time on conversion of $\mathrm{L}$-ascorbic

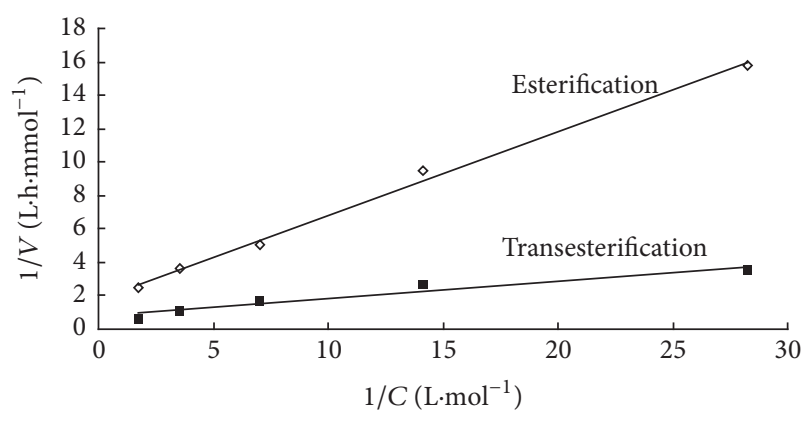

FIgURE 6: The Lineweaver-Burk plot of $1 / V_{0}$ versus $1 /[S]$.

acid were investigated to optimize the conditions. Since Lascorbic acid was dissolved in tert-butanol with a saturated concentration of $26 \mathrm{mmol} / \mathrm{L}$, the effect of concentration of flurbiprofen or flurbiprofen methyl ester on the rate of reaction was investigated systematically over a wide range with a constant $\mathrm{L}$-ascorbic acid concentration. For the determination of initial rates, esterification and transesterification were conducted by using $55 \mathrm{mg}$ Novozym 435 lipase with appropriate quantities of acyl donor (flurbiprofen or flurbiprofen methyl ester) and L-ascorbic acid. In esterification and transesterification experiments, the amount of flurbiprofen was varied from 35 to $568 \mathrm{mmol} / \mathrm{L}$ at a fixed quantity of L-ascorbic acid $(26 \mathrm{mmol} / \mathrm{L})$. The initial rates were determined for each experiment. From the initial rate determined, it showed that when the concentration of acyl donor (flurbiprofen or flurbiprofen methyl ester) was increased, by keeping the concentration of L-ascorbic acid constant, the initial rate of reaction increased proportionally. This presumed that there was no evidence of inhibition by acyl donor (flurbiprofen or flurbiprofen methyl ester) at all the concentrations tested. According to the rate equation for the ping-pong bi-bi mechanism without substrate inhibition [15], the LineweaverBurk plot of $1 / V_{0}$ versus $1 /[S]$ in Figure 6 showed the kinetic parameter values. The apparent Michaelis-Menten kinetics are $K_{\mathrm{rn}}=0.29 \mathrm{~mol} / \mathrm{L}$ and apparent $V_{\max }=0.563 \mathrm{mmol} / \mathrm{L} \cdot \mathrm{h}$ for flurbiprofen. Apparent Michaelis-Menten kinetics are $K_{\mathrm{rn}}=0.14 \mathrm{~mol} / \mathrm{L}$ and apparent $V_{\max }=1.34 \mathrm{mmol} / \mathrm{L} \cdot \mathrm{h}$ for flurbiprofen methyl ester. This indicated that Novozym 435 lipase has higher affinity for flurbiprofen methyl ester and lower affinity with flurbiprofen. Transesterification has higher reaction rate than esterification.

\section{Conclusion}

The L-ascorbyl flurbiprofenate has been synthesized successfully by lipase-catalyzed transesterification and esterification in tert-butanol. The goal of this work was to compare lipasecatalyzed esterification and transesterification approaches. Both approaches were studied in a systematic way including the effect of various parameters. We have tried to optimize lipase-catalyzed esterification and transesterification to ensure meaningful and objective comparison among different approaches. Synthesis of L-ascorbyl flurbiprofenate was influenced by reaction conditions. The equilibrium shift 
towards the L-ascorbyl flurbiprofenate synthesis was limited in spite of the presence of an excess of acyl donor. The most important strategy seemed to be the efficient removal of by-products, such as water or methanol. Addition of molecular sieves $3 \AA$ during reaction could control water activity of the system. However, addition of molecular sieves $3 \AA$ during reaction could not control methanol content. It was observed that the rate of the transesterification was much higher than that of esterification within $24 \mathrm{~h}$. If the experiments were conducted for a long time, the conversion would reach asymptotic values and then the conversion of esterification was higher than that of the transesterification. This reflected a greater reactivity of flurbiprofen methyl ester in the lipase-catalyzed transesterification reaction as compared with esterification. However, the inherent drawback associated with lipase-catalyzed transesterification was the production of methanol and the equilibrium was usually not in favor of transesterification. Also, in the transesterification, flurbiprofen had to be chemically converted to its methyl ester and then subjected to the transesterification catalyzed by lipase. Although the rate of esterification is slower than that of transesterification, if a choice is at all available, from the standpoint of productivity and the amount of steps required, lipase-catalyzed esterification has been judged to be superior for the synthesis of L-ascorbyl flurbiprofenate.

\section{Competing Interests}

The authors declare that they have no competing interests.

\section{Acknowledgments}

The authors thank the National Natural Science Foundation of China (21573055), the Scientific Research Fund of Heilongjiang Province (GC13C111), the Open Project Program of the State Key Laboratory for Oxo Synthesis and Selective Oxidation, and the State Key Laboratory of Chemical Resource Engineering for support.

\section{References}

[1] Y. Zhao, B. Y. Qu, X. Y. Wu et al., "Design, synthesis and biological evaluation of brain targeting L-ascorbic acid prodrugs of ibuprofen with 'lock-in' function," European Journal of Medicinal Chemistry, vol. 82, pp. 314-323, 2014.

[2] B. P. Imbimbo, "The potential role of non-steroidal anti-inflammatory drugs in treating Alzheimer's disease," Expert Opinion on Investigational Drugs, vol. 13, no. 11, pp. 1469-1481, 2004.

[3] L. Gasparini, E. Ongini, D. Wilcock, and D. Morgan, "Activity of flurbiprofen and chemically related anti-inflammatory drugs in models of Alzheimer's disease," Brain Research Reviews, vol. 48, no. 2, pp. 400-408, 2005.

[4] S. Côté, P.-H. Carmichael, R. Verreault, J. Lindsay, J. Lefebvre, and D. Laurin, "Nonsteroidal anti-inflammatory drug use and the risk of cognitive impairment and Alzheimer's disease," Alzheimer's \& Dementia, vol. 8, no. 3, pp. 219-226, 2012.

[5] X.-Y. Wu, X.-C. Li, J. Mi, J. You, and L. Hai, "Design, synthesis and preliminary biological evaluation of brain targeting Lascorbic acid prodrugs of ibuprofen," Chinese Chemical Letters, vol. 24, no. 2, pp. 117-119, 2013.
[6] S. Manfredini, B. Pavan, S. Vertuani et al., "Design, synthesis and activity of ascorbic acid prodrugs of nipecotic, kynurenic and diclophenamic acids, liable to increase neurotropic activity," Journal of Medicinal Chemistry, vol. 45, no. 3, pp. 559-562, 2002.

[7] Y. Laras, M. Sheha, N. Pietrancosta, and J.-L. Kraus, “Thiazolamide-ascorbic acid conjugate: a $\gamma$-secretase inhibitor with enhanced blood-brain barrier permeation," Australian Journal of Chemistry, vol. 60, no. 2, pp. 128-132, 2007.

[8] Z. Wang and L. H. Tang, "Design, synthesis and characterization of ascorbic acid pro-drugs of flurbiprofen," Strait Pharmaceutical Journal, vol. 22, no. 110, pp. 213-217, 2010.

[9] X. N. Liu and L. H. Tang, "Kinetics and thermodynamics of Lascorbyl profen esters synthesis catalyzed by lipase in 2-methyl2-butanol," Chinese Journal of Bioprocess Engineering, vol. 8, no. 6, pp. 33-39, 2010.

[10] J. L. Eriksen, S. A. Sagi, T. E. Smith et al., "NSAIDs and enantiomers of flurbiprofen target $\gamma$-secretase and lower A $\beta 42$ in vivo," Journal of Clinical Investigation, vol. 112, no. 3, pp. 440449, 2003.

[11] H. Geerts, "Drug evaluation: (R)-flurbiprofen-an enantiomer of flurbiprofen for the treatment of Alzheimer's disease," The Investigational Drugs Journal, vol. 10, no. 2, pp. 121-133, 2007.

[12] C. Hansch, A. Leo, and D. Hoekman, Exploring QSAR: Hydrophobic, Electronic, and Steric Constants, American Chemical Society, 1995.

[13] C. Hansch, A. Leo, and D. Hoekman, Exploring QSARHydrophobic, Electronic, and Steric Constants, American Chemical Society, Washington, DC, USA, 1995.

[14] Q.-X. Song and D.-Z. Wei, "Study of Vitamin C ester synthesis by immobilized lipase from Candida sp.," Journal of Molecular Catalysis B: Enzymatic, vol. 18, no. 4-6, pp. 261-266, 2002.

[15] G. D. Yadav and P. S. Lathi, "Intensification of enzymatic synthesis of propylene glycol monolaurate from 1,2-propanediol and lauric acid under microwave irradiation: kinetics of forward and reverse reactions," Enzyme and Microbial Technology, vol. 38, no. 6, pp. 814-820, 2006. 

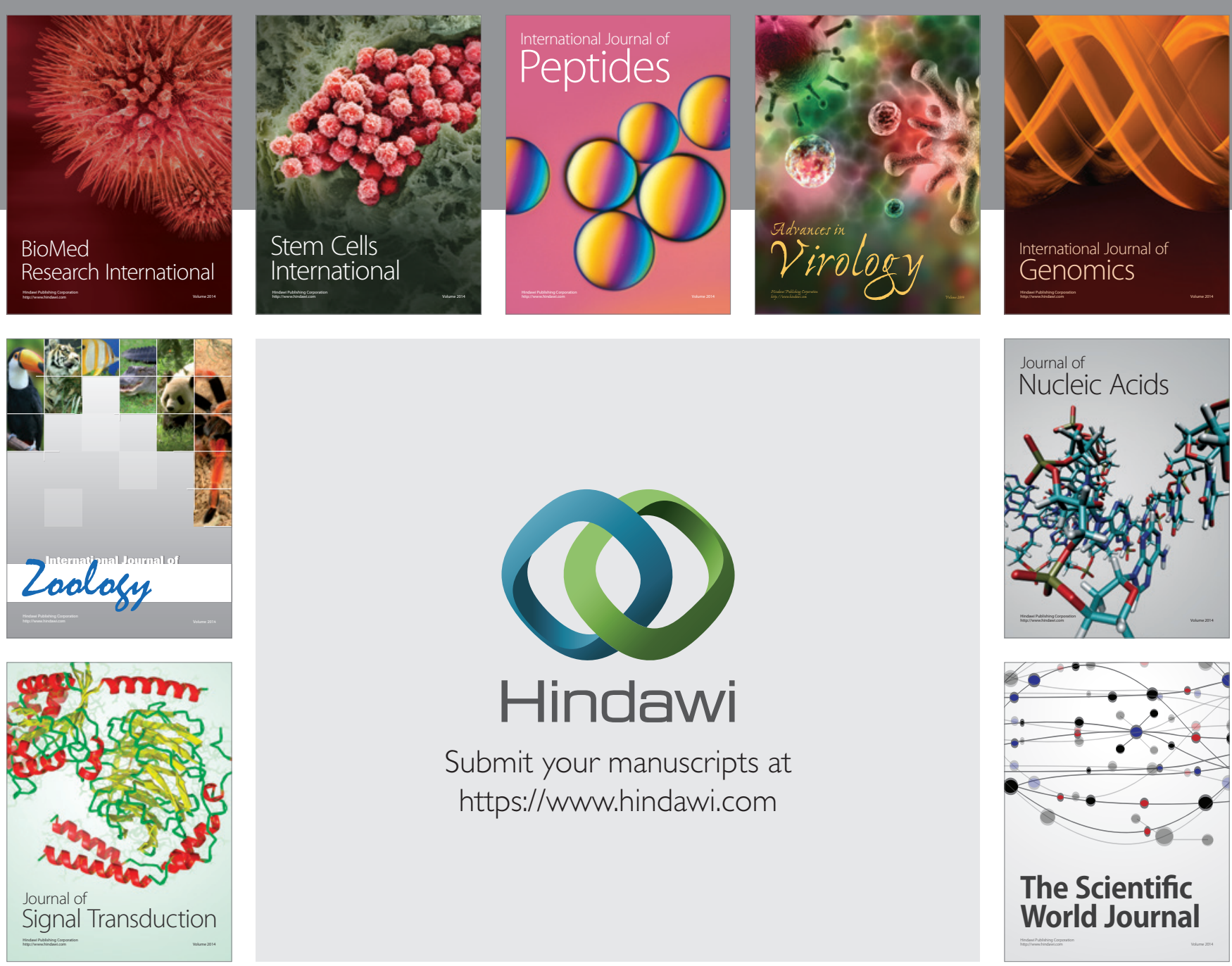

Submit your manuscripts at

https://www.hindawi.com
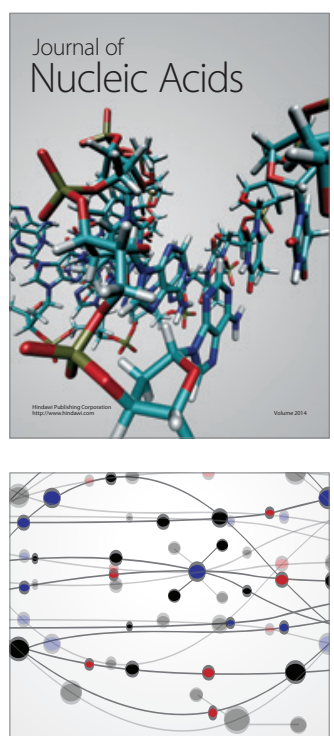

The Scientific World Journal
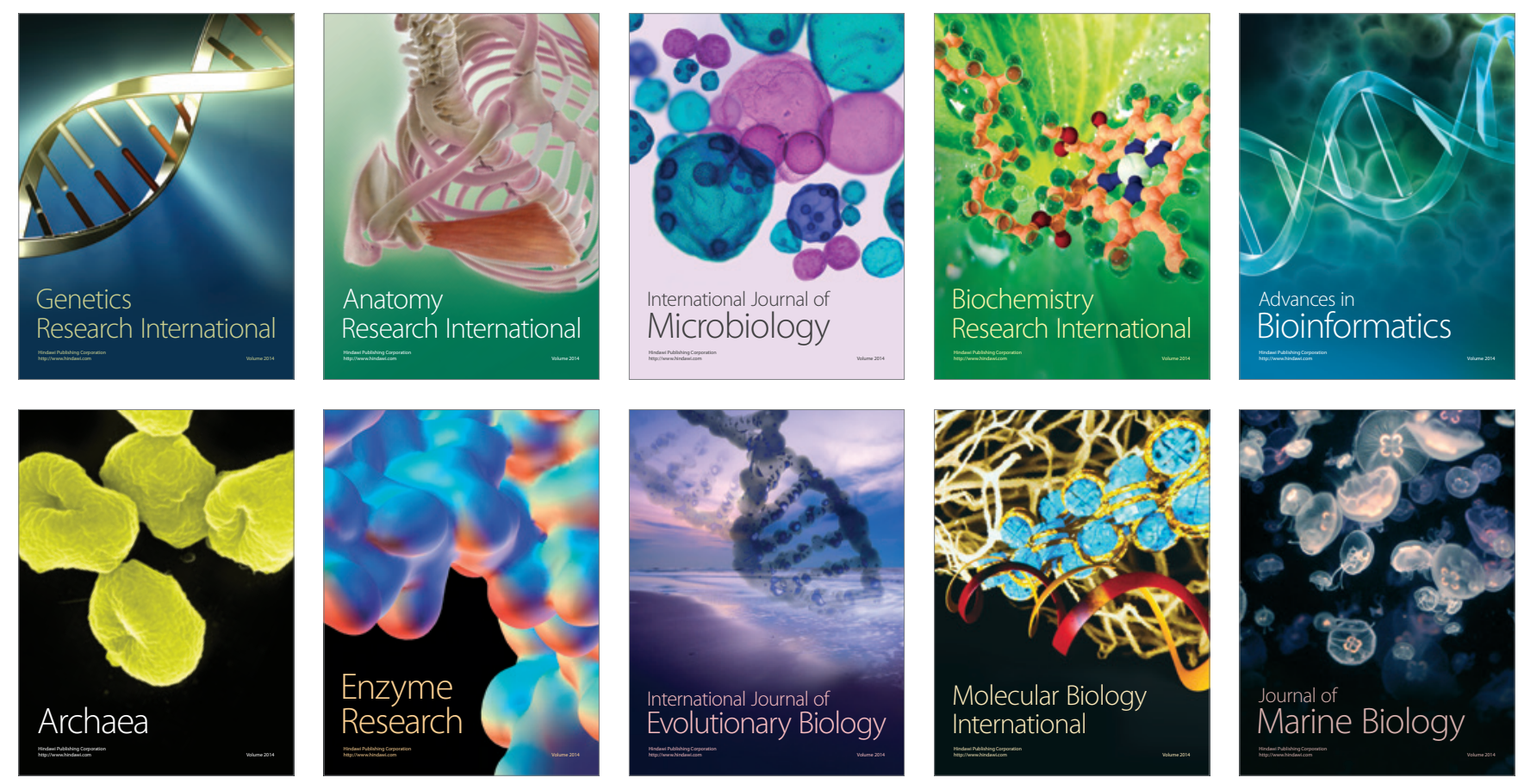